This material is not to be cited.

\title{
Thou Art, I am: Discovery and Recovery in the Art Making Process
}

Olivia Sagan

This chapter explores the experience of making visual art and its interface with mental wellbeing. It draws on data from empirical narrative research with mentally ill artists (Sagan, 2014). Observant of the lived experience of participants and of the meanings made by them of their particular processes of making art, the research is couched within what is still known as the 'new paradigm' for psychology (Smith, Hare \& Langenhove, 1995). This paradigm, borne of the well-founded worry that the application of psychology dehumanised people (Reason \& Rowan, 1981) is one driven more to understanding and description than to measuring - and towards determining social rather than statistical significance. The messages of research within this paradigm are often side-lined, not considered as offering hard evidence. However, these messages provide important insights into the experience of being human and how that human makes sense of that experience as part of her very being.

The research drew on a psychoanalytic, Object-Relations approach to aesthetic understanding (Glover, 2009). This identifies the unconscious and our relationships real, imagined, longed for or feared - as active ingredients in the making of art. The chapter asks what it is we are seeking or finding in what Dissanayake (1990) termed the process of 'making things special'. It explores artistic activity as a unique means of unearthing and addressing a sense of 'original deficit' (Wright, 2009:49) which is often part of the package of mental illness. The conceptual direction of the chapter is towards an alliance between psychoanalytic concerns with the relational and the phenomenological (Atwood \& Stolorow, 2014), with its pursuit of the texture of emotional experience.

The conclusion makes a brief case for the place of such research and the insights such theory affords. It asks that observant, qualitative study of human experience be used to complement the 'hard' data of statistical methods and randomised control trials by offering a 'beyondness' to our questioning and an 'acceptable unresolvedness' to our answers. It urges that 'negative capability' (Keats, 1970) the ability to tolerate 
uncertainties, as developed by the psychoanalyst Wilfred Bion (1970), be a more valued element in both research and policy, as a move towards emotionally intelligent policymaking (Cooper, 2015).

\section{Background}

After more than a decade of speaking to people who hold that making art contributes in many and subtle ways to their mental wellbeing, I have to confess that I still don't 'know' how making art works. How does it help people through depressions and breakdowns? How does it support them through a formidable array of symptoms and darknesses, instances of pharmacological (mis)interventions and through bleak episodes of the errant side effects of medications? How does it offer something - at times of loss and mourning; addiction and compulsion; Ioneliness, trauma and the both terrible and exhilarating rollercoaster of bipolar conditions - when seemingly all else fails to offer anything?

Research that investigates the impact of making art on one's mental wellbeing is now a vibrant canon of work. It is a body of work encompassing inter/national collaborations, numerous methodologies, diverse conceptual perspectives and findings both quiet and triumphant. These indicate that art making, particularly in community settings (White, 2009), can lead to an overall improvement in general health; to an improved quality of life and strengthening of self-esteem (Odell-Miller, et al, 2006; Van Lith et al, 2013); that it contributes to a feeling of being valued; facilitates interpersonal relationships and a strengthening of social ties (Camic, 2008; Griffiths, 2008; Staricoff, 2004; Mowlah et al 2014 ); and that art making offers an effective way of exploring personal issues (Heenan, 2006) and of facilitating self-discovery (Lloyd, Wong \& Petchkovsky, 2007). It suggests that art making can function therapeutically as cognitive distraction (Drake \& Winner, 2012); as an alternative to art therapy for vulnerable groups (Argyle \& Bolton, 2005) and as a means by which to foster hope (Sagan, 2015) and rebuild identities (Spandler et al 2007).

There now resides a body of evidence that demonstrates that art making positively impacts on our mental wellbeing. But research in this area continues to be riddled with challenge. There is the perennial problem that measuring $X$ (in this case art making) and its impact is far from explaining how (and if) $\mathrm{X}$ has effected that impact. In fact, 
many studies are far from clear what ' $X$ ' is; how it is encountered; by whom - and what the myriad variables of any of the components of psychoemotional improvement might be. While such challenges within qualitative studies arguably contribute to a perceived lack of evidence base and by extension to limited policy responses, the challenges themselves tell us a great deal about the nature of art making; of mental illness; and the complex and unique interface between the two. So while we edge towards further refinement of tools and methodology, towards a greater sophistication of metrics and observation; and towards an employment of an even larger panoply of technical tools and instruments now embracing the exciting possibilities of neuroscience, this chapter and its attendant research seeks to do something smaller and quieter. It makes use of biographic data from three qualitative studies (Sagan 2010; 2011; 2014) and revisits it, asking again what the experience of making visual art as an adult with enduring mental health difficulties is. Does this chapter provide evidence? No, unless like me you hold that one person's experience is evidence. Does it explain how art works? Perhaps not, but some hard-wearing and worthy ideas are revisited and proffered. Is this enough? Well, l'll let the reader decide.

\section{Methodology}

The data drawn on in this chapter span several years and projects, all aimed at gathering 'thick' first person narrative data from adults with enduring mental health issues who were also practicing artists. The main project, funded by the Arts Council (Sagan 2011) arose from a series of consultation meetings with mental health service users involved in artistic activity.

In total approximately 60 people gave full length interviews which were recorded, transcribed verbatim and in most cases anonymised. In the cases where participants preferred to disclose their identity this was only done if it would not compromise the identity of another participant by association. Ethical clearance was granted by the host universities at the time. Recruitment took place through calls announced through mental health and art networks and through word of mouth in the South East of Britain. Participants in this sample self-identified as being White British, Black British or Asian and were all formally diagnosed as having a mental illness, with diagnoses including schizophrenia, Borderline Personality Disorder (BPD); Dissociative identity Disorder 
(DID), Obsessive Compulsive Disorder (OCD); chronic depression; Bipolar disorder; psychosis and anxiety.

Recorded semi-structured interviews lasted in between 45 and 90 minutes, and there was an option to be interviewed more than once. Indeed, around 40 of the participants chose to have a longer term relationship with the process, being interviewed on other occasions and offering further thoughts and reflections on the questions raised for them, sometimes by written account. The span of participation for this group ranged from $1-5$ years. The interview was guided by the schedule rather than dictated by it, allowing for elaboration and digression which invariably was where the rich biographic detail resided within a tradition of interviewing that allows for this (Kvale, 2003). Transcripts were analysed according to the principles of thematic analysis (Braun \& Clarke 2006), which offered sufficient flexibility and clarity to approach and interpret the data through a phenomenological lens. Interpretation and understanding drew on an iterative process of analysis, re-reading and refining, moving attentively between the descriptive and the interpretative processes.

A principle of redundancy was applied when sufficient representative data had been extracted to suggest the emergence of salient themes. Influenced by feminist ontoepistemological principles, narrative work of this type continues to remind us of the value of reflexive, first person interviews that function as a resource on which people can draw as part of their re-scripting and narrative rebalancing. As such the approach holds particular currency for work with adults experiencing the compound injuries of mental ill health; the silencing and voicelessness of traumatic pasts, and futures commonly pre-saturated in the language of deficit. The deliberate 'slowness' of the narrative interview, and the flexibility to return to the participant should $s /$ he wish to elaborate on something after having had time to reflect, coupled with the freedom to present and talk about the art works themselves, lent a special opportunity for people to consider and reflect upon their lives and their work and the role of the latter in interaction with the former. It is work that positions the individual as the unit of analysis (Figert 2010).

\section{Findings}




\section{Thou art / I am}

The narratives in this research fall largely into the category of 'redemption' narratives (McAdams, et al, 2001) in which 'the storyteller depicts a transformation from a bad, affectively negative life scene to a subsequent good, affectively positive life scene' (lbid:474). The narratives can also be seen to fall into Arthur Frank's (1995) third category, the 'quest' narrative, in which a journey is described in which adversity is now being faced head on, in the belief that something is gained, or to be gained from the experience. However, it was not an intention of the research to further refine or categorise types of narrative - rather, to stay close to what each participant said of their experience and how they made sense of that experience.

What was striking in this data is that the participants attributed this narrative, its content and direction, to their art making, and the narrative identity developed through this. It is this project of building a narrative identity (Ricoeur, 1986) which was held to be a unique aspect of art making and its powers of 'finding the words to say it'. As Liz put it:

So all the art work and all the healing that has happened in the last 7 or 8 years has really been about trying to find another language for the thing I didn't know how to talk about or the thing I didn't have language for...

Astrid also described how:

... stuff that is within you can be revealed [makes a gesture of a bud opening] through the painting and the drawing... it's something there that you've made, it gives you a connection with something that is outside of you but still part of you. And that then feeds back into how you understand yourself, how you think of your self... and into how you work...

Here it is worth noting that while narrative processes can be agentic and life affirming, they may also reproduce toxic stories: some of the participants spoke at length about the perceived limitations of therapy, their weariness and wariness of clinically induced illness-dominated identities (Scheff, 1999). In some cases they believed that such stories would condemn them further and were often guarded in responses, especially 
at the outset of the interview process. Yet art, it seems, in its making and at times through its destruction or rejection offered a conduit for connecting with fragments of themselves, perhaps forgotten; disavowed; or indeed deliberately avoided. Over and again, participants described the experience of reifying an emotion or experience in a way that words did not allow. Tara said simply that the story of things that happen to us is '...deep, too deep for language, but not too deep for the eye.'

The philosopher Susan Langer spoke of art as articulating the very shape of human feeling in a way words can never do (Langer, 1930). Given the ambivalence towards words and verbal expression felt by many with histories of silences, lies, trauma, secrets and illness, the value of an alternative form for narrative exploration can not be over stated. The building of an identity through one's work in a process that was one not pathologised, static or circumscribed by diagnosis or clinical setting was held to be an invaluable component of art making. It was owned and not open to manipulation by experts; it was highly valued, not least for the recognised change in one's relationship with others as a result. Here Laura comments:

When I paint...[pause] as an artist, it's like l'm becoming, like I am someone else, something more than what's gone on before... and this me seems better at being with others...does that make sense?

At times this relational work was directly undertaken through the art making itself, where, in Tom's words:

I 'do' repair. I have to work with others all the time in my work, and I'm always having to ...to...work at working with others and repair relationships when they go wrong, something l've never, ever been able to do before my art, making it...

More poignant still, were the narrative strands that alluded to this 'deficit' in one's relational world stretching way, way back to primary experiences. Poignant too, were the quiet descriptions of the experienced body blow of the suspicion that this was where, in Paul's words 'all this [signals the head] started...' 
So one thing that these narratives appeared to allude to, time over time, was a process of narrative identity being wrought through one's making of imagery, and indeed through its very processes. Zak, an abstract painter who dismissed the 'auto content in my work' nevertheless mentioned how he gradually noticed his way of storing 'art works that had touched a nerve in a particular "lesser" place in my studio'. Whereas some participants claimed they had felt stymied in talking therapies which 'trapped me' in 'well-worn' stories, perhaps because of the shortcomings of words and verbal expression to people whose main representations of the world were in image and symbol, art making offered something particular in relation to identity: discovery; through one's own means, at one's own pace, in a non-clinical setting.

\section{Discovery}

Integral to this perceived building of an ' $l$ ' with its potential for new means of relationship with others was a discovery and integration of parts of the self, even those previously evacuated or denied, which according to Klein are also the 'source of inspiration in artistic productions' (1958:245). Here's Tobias: on 'stumbling' on an image:

I grew up in Cumbria and ...I love wild imagery ...natural images, and when I was painting what I thought was 'a landscape' I suddenly recalled being with my dad, out on the hills [pause].... it was about the experience [pause]...l don't know...[pause]...the memory, one l'd not thought of for, well decades... it came into my painting, and triggered a lot of other things about my experiences at that time....with my dad...I reckon I discovered something about myself...and him...that I never knew. But now it was there. Part of me. Kind of owned? Painted.

The point made by Tobias, that making art unearths experiences which then become part of one's narrative and artistic genre is one that crops up throughout artists' stories. It is part of the theme of 'discovery' that was so prevalent in this research. Ricoeur (1991:30) suggests that it is in such eruptions of 'something else', where something beyond words and consciousness emerges, that the 'teller' is jolted into a new way of thinking and even being - and thus identity evolves. 
Unearthing these experiences and transforming them in some way into images was felt to be pivotal in the relationship between making art and developing an 'l' with which to negotiate the 'Thou' better. Here's Yelena:

Art brings me into contact with sides of my personality that are surprising, and it's a journey... an exploration...It creates better understanding and connection to people and the world around me. It's a discovery as well as a memory.

The process of making was of paramount importance because in this process, unknown or concealed experiences and their attendant emotions emerged and then, as a consequence, became speakable, part of one's narrative identity. But this journey, one of discovery, was far from easy. Charlie said the ongoing process of 'uncovery' meant he had to get used to living 'on the peripheries of myself' and losing a sense of self before finding it, with all the attendant anxiety of that process. Maria Walsh, in writing about this repeated artistic anxiety, described it as 'pleasurable unpleasure' (2013:114).

Here's Katie describing how images and thoughts emerged as she was painting 'something quite unrelated' which led to her reassessing her psychiatric history and the role of her family and others in it:

I kept coming back to being in hospital - over and again these images would present themselves and I just started wondering...how did I get there? What was I doing there, 19 years old, without anyone asking me, really talking about what had happened? That all seemed so wrong, suddenly, but god knows why it took so long for me to ask that...

Art making was spoken of as involving risk both in its discovery journey and in the element of disclosure, the revealing, sometimes publicly, of that ' $l$ '. Reflections sometimes led to painful acknowledgments of the forces arrayed in opposition to mental health; the discrimination, inequality, stigma, losses; poverty - and the bleak impact of market forces which require that many of us stay ill. As put by Ayden: 
They need us to buy their drugs...buy into their therapies... we being ill makes them well...I started seeing that...

In the recordings, streaked through with sobs, laughter, thick pauses and utterances of exasperation or wonder, the intricate processes of discovery and of affirming an I in relation to a Thou, were described. But these processes were interlinked with a further narrative strand: that of recovery and participants' diverse, often ambivalent relationships with it.

\section{Recovery}

Unsurprisingly, references to recovery formed a part of the narratives, and this was explored further, not least because it was the narrative strand that most revealed notable shifting of positions.

Most of the people willing to tell me their story had reached a point where they felt well enough and defiant enough to tell that story. Known to each narrator was the risk of returning to a more ill state, the prospect of relapse to a voicelessness where, as Jil put it, you just had to 'stay put, stay quiet... try and survive...'

Narratives revealed an armoury of health maintaining strategies, a list topped by art making. It included daily rituals and thought regulation; better self-management and dietary control; meditation, vigilance, connections with self and peer help groups - and medication, even hospitalisation. It was repeated time and again that any or all of one's symptoms of ill health might return, yet people were for the most part adamant you emerged again by using your own resilience and panoply of life-learned strategies. One of the ways through which energy was found to face this recurring battle was through a belief in the tenets of the recovery movement.

Recovery discourse emerging through research themes is noted elsewhere in the literature (Bonney \& Stickley, 2008) and in the present data it was clearly detectable in people's stories. Indeed, the recovery discourse was, in some cases, viewed to have directly enabled an alternative life narrative - one of resistance to the labels felt to 
have been applied before. In today's therapeutic culture wherein we increasingly construct our problems in professional, medico-scientific language, this more agentic discourse of recovery offers welcome relief, and a cluster of broadly aligned principles have motivated, reassured and galvanized huge numbers of people with mental illness. Particularly widespread in the UK, Canada, Australia, New Zealand and America, the recovery movement offers a counter-narrative to the psychiatric story of mental illness, one which 'belongs to consumers-survivors' (Schiff, 2004:212). It was notable in this data, how many of the participants 'spoke' the language of recovery, with its people-first descriptors (person in recovery; person with schizophrenia) and its focus on positivity and on individual strengths. So a further undertaking of the research was to explore what use was made of this discourse in conjunction with an art practice, and whether an oppositional identity was enabled. How did this narrative of recovery appear to intersect with that of an art practice?

Amidst the many references to recovery was a dominant strand of narrative that specifically described how art practice and one's recovery were interlinked. As Neenah put it, 'My art practice has been very central to my recovery - it has been there, in tandem'. For some, there was no separating them. Paul insisted they were the 'same thing, so can't talk about one without the other [shrugs]'. For Josh, similarly:

...my art practice is my recovery...I don't get to have one without the other... it's just not part of the deal.

People also referred to the meandering of their 'recovery journey', describing coming to accept an illness and what had happened to them. They spoke of insights into this journey gained, in some cases, exclusively through the making of art as part of its discovery and of facing, at times, one's hidden 'demons'.

But was the recovery discourse yet another potentially limiting narrative? And did an art practice do anything to challenge this? Harper \& Speed (2012) maintain that the very concepts of recovery and resilience are individualistic and based on medicalized and neoliberal notions of individual responsibility; a discourse that 'simply reframes deficits as strengths and is thus implicitly reliant on deficit-based models' (p.10). They also note that structural inequalities are routinely de-emphasized within the neoliberal 
framework. Indeed, this sense of individualism, compounded by the enduring notion of artist as individual was identifiable throughout the interviews with artists. Yet this lone-artist, intrapersonal allusion was almost always countered by descriptions of the interpersonal nature of one's art practice; you communicated to somebody - and an art practice was invariably felt to play a substantive role in supporting relationality.

So while the ' $l$ ' in the narratives of art prevailed, that ' $l$ ' was 'found' in a relational capacity through one's art making. Sometimes this was through the pragmatics of being with others in creative collaborations, in Catherine's words:

... that thing of being 'part of a group' [makes scare marks] has been really good for me...That's one of the things that comes from being involved with the arts, being part of a group, who are working on something.

Other times, it was through the more subtle narrative rebalancing, trialling and testing mentioned earlier on. Parr (2012:8) noted that art can be 'an important 'stepping stone' into wider social geographies' and it seemed these social geographies were both literal and envisaged, a connecting with others through one's work, as one worked.

But did an art practice in any way unseat the 'deficit' contained, nevertheless, in the recovery discourse? Participants spoke, as described, in a 'language' saturated with that of recovery. Yet this language appeared to function in tandem with an art practice to nurture a more reflective, sometimes confrontational identity. The language and practice combined seem to have been instrumental in some individuals' moving away from the pernicious psychiatric discourse of terminal pathology. They became someone other than patient; paranoid-schizophrenic; survivor. They became an artist; a collaborative partner; a painter; maker; someone else, and most importantly for them, someone more. This was further enhanced through exhibition opportunities; collaborative project work; workshop participation, and general broader exposure. Here's Sarah: 
I was really cautious to begin with, really, really cautious...I was aware that I was going to be doing something a bit controversial, but then I think I just got a bit rebellious as well... because I thought, if someone has a sore leg they can talk about their sore leg and it's absolutely fine. If someone has mental health problems, why is there such a stigma around it? Why can't they talk about this also? I just felt rebellious and thought, well l'm just going to talk about it because if I talk about it then maybe someone else will talk about it.

Art making time and again also seemed to facilitate an engagement with the political, triggered by the processes of self-analysis and expression that appeared to be the foundation stones of people's art practice. The interpersonal in art practice, taking the form of an imagined conversation with one's abuser; a symbolic revisiting of relations with sometimes deceased family members; a rehearsed dialogue with a spectator; interaction in an arts community, conversations with a potential buyer or indeed realised stories to one's therapist - served as a catalyst for positive social transformation.

The recovery narrative took people so far, and one can argue this has limited longer term political gain, speaking as it does in a language of deficit. But for these artists it was the art practice, one initially fortified by recovery principles - which then took them beyond the rhetoric. This move beyond pulled them towards a narrative of greater resistance and insight which in some cases led to direct activist involvement; or an allegiance with the many types of art practice nestled under the umbrella participatory art (Bishop, 2012). Parallel to this fledgling narrative identity a vitalized, more integrated self was experimenting with interpersonal manoeuvre and in many cases, functioning more potently within wider social relations.

This narrative identity emerged as an outcome of the self-analytic journey which appeared inescapable through a sustained art practice, even for those who had shunned or eschewed this element to begin with. Through this analytic process, which was often claimed to not have been verbally articulated to one's self, but 'carried' in 
imagery and process, a more coherent, congruent narrative identity was felt to be forged. This was one that rejected not only psychiatric labels, but 'post' labels too; Outsider Artist, for example, was not considered by most to be an identity aspired to, and some equally shunned terms such as 'survivor'. Art making, it seems, was enabling the progressive and regressive autobiographic process that Ricoeur (1986) argues is part and parcel of narrative balancing.

\section{Conclusion}

This chapter has offered a condensed overview of the salient findings of a number of studies. As such it has obvious limitations, among which would be the inconsistencies inevitable when constructing a corpus of data from different projects.

And although each project took the same approach to interviewing, with close attention given to enabling free-associative biographic detail to emerge, in an approach that acknowledges The objects and events of experience are never free-standing but depend for their meaning on their context in the lifeworld' (Ashworth, 2016:22) for reasons of brevity there is limited presented contextual detail of participants. A largely self-selecting sample too, weakens and narrows the experience range; so the reader is urged, in her reading, to be mindful of the voices which are not presented because not heard, because silent, perhaps because silenced.

The chapter, and the research behind it, maintains that for many artists, art functions in their lives as a reparative means of unearthing and even addressing a 'nagging sense of loss' as Ciara put it, a 'void' as others named it, or a nameless lack. This echoes Wright's (2009) sense of 'original deficit' often part of the experience of mental illness - but also, one might argue, part of being human. Art making was experienced as reparative; it repaired old and sometimes unacknowledged, or disavowed wounds. It repaired a sense of I, with which to forge a more meaningful 'we' in repaired or more 'ease-full' relationality. Many of these aims or experiences are indeed the staple of psychoanalytically informed art therapy; but these experiences spoken of had been forged on one's own, in a non-clinical, and non-expert driven context, and this in itself may have been the active ingredient in achieving a more agentic and congruent narrative identity. 
Art-based practices have attracted increasing support in mental health settings in the past decade in particular. These offer a positive, recovery-oriented, sometimes radical approach that attends to the emotional, the social and even the spiritual needs of people on their path through illness and wellness. Yet the described benefits of making art and their domains cannot easily be disentangled. The temporal, spatial and subtle experience of making art bestows minutely varying benefits in different domains at different times and indeed, at different points of a person's recovery or illness. Repeated contact with the experience of making art nurtures it, accumulating over time to produce transformation (DeNora, 2013) and so cannot usefully be gauged, substantively through short term interventions and snapshot evaluation. Art and its making and unmaking, consumption and displaying, is a complex activity to which we bring multifaceted selves with myriad intersections - and it is time that we put the 'does it work' question behind us. Let's move on more creatively to exploring and watching the 'how'. It is slow, patient, observant work; requiring the ability to suspend judgement; bear uncertainty and stay still amidst the construction noise generated by the building of hierarchies of evidence (Clift, 2012).

A deliberate slowness and uncertainty in research processes are anathema to our current demands for academic quick-wins within a 'hard evidence' hungry culture. These demands are a poor response, aligned though they are with our short term, non-deliberative approach to policy making in a particular socio-political moment. Such an approach to research and policymaking demands rather than asks; exhorts rather than suggests and draws comfort from the imagined security of numbers as explanations for the opaque uncertainties of being human. In so doing, we are missing too, the nuanced brilliance of being human. 


\section{References}

Argyle, E. \& Bolton, G. (2005), 'Art in the community for potentially vulnerable mental health groups'. Health Education, 105 (5) : 340-354

Ashworth, P.D. (2016), 'The lifeworld - enriching qualitative evidence'. Qualitative Research in Psychology, 13 (1) : 20-32

Atwood, G. E. \& Stolorow, R. D. (2014), Structures of Subjectivity. Explorations in Psychoanalytic Phenomenology and Contextualism. (2nd Ed.) London, Routledge. Braun, V. and Clarke, V. (2006), 'Using thematic analysis in psychology.' Qualitative Research in Psychology, 3 (2). pp. 77-101. ISSN 1478-0887

Bishop, C. (2012), Artificial Hells: Participatory Art and the Politics of Spectatorship, London: Verso Books

Bion, W.R. (1970), Attention and interpretation. London: Tavistock Publications, 1970 Bonney, S. and Stickley, T. (2008), 'Recovery and mental health: a review of the British Literature', Journal of Psychiatric and Mental Health Nursing, 15: 140-153 Camic P.M. (2008), 'Playing in the mud: health psychology, the arts and creative approaches to health care', Journal of Health Psychology 13:287-298.

Clift, S. (2012), 'Creative arts as a public health resource: moving from practicebased research to evidence-based practice,' Perspectives in Public Health 132 (3) $12-127$.

Cooper, A. (2015), 'Containing tensions: Psychoanalysis and modern policymaking', Juncture, 22 (2): 157-163.

DeNora, T. (2013), "'Time after time", A Quali-T method for assessing music's impact on wellbeing,' International Journal of Qualitative Studies in Health and Wellbeing, 1: $1-13$

Dissanayake, E. (1990), What is Art for? Seattle, WI: University of Washington Press.

Drake, J.E. \& Winner, E. (2012), 'Confronting sadness through art-making:

Distraction is more beneficial than venting', Psychology of Aesthetics, Creativity and the Arts, 6(3): 255-261

Figert, A. E. (2010), "The Consumer Turn in Medicalization: Future Directions with Historical Foundations,' in The Handbook of the Sociology of Health, IIIness and Healing: Blueprint for the 21st Century, edited by B. Pescosolido, J. Martin, J. McLeod, and A. Rogers. New York: Springer, Pp. 291-308 
Frank, A.W. (1995) The Wounded Storyteller, Chicago: The University of Chicago Press.

Glover, N. (2009), Psychoanalytic Aesthetics: An Introduction to the British School, London: Harris Meltzer Trust and London: Karnac Books.

Griffiths S. (2008), 'The experience of creative activity as a treatment medium.' Journal of Mental Health, 17 (1)49-63.

Harper, D. and Speed, E. (2012), 'Uncovering Recovery: The Resistible Rise of Recovery and Resilience', Studies in Social Justice, 6 (1): 9-25

Heenan D. (2006), 'Art as therapy: An effective way of promoting positive mental health?' Disability \& Society, 21 (2): 179-191.

Keats, J. (1970) The letters of John Keats: A selection. Ed. Gittings, R., Oxford: Oxford University Press.

Klein, M. (1958), 'On the development of mental functioning', Envy and Gratitude and Other Works, London: Hogarth Press: 236-246.

Kvale, S. (2003). 'The psychoanalytic interview as inspiration for qualitative research'. In: Camic, P., Rhodes, J. \& Yardley, L., eds. Qualitative Research in Psychology: Expanding Perspectives in Methodology and Design. Washington, DC: American Psychological Association Press: 275-297.

Lloyd C, Wong, S.R, \& Petchkovsky L. (2007), 'Art and recovery in mental health: A qualitative investigation'. British Journal of Occupational Therapy, 70 (5): 207-214. Langer, S. K. (1930), 'The Practice of Philosophy', New York, NY: Henry Holt. McAdams, D.P., Reynolds, J., Lewis, M., Patten, A.H. and Bowman, P.J. (2001), 'When Bad Things Turn Good and Good Things Turn Bad: Sequences of Redemption and Contamination in Life Narrative and their Relation to Psychosocial Adaptation in Midlife Adults and in Students', Personality and Social Psychology Bulletin, 27(4): 474-485

Mowlah, A., Niblett, V. Blackburn, J. Harris, M. (2014), The Value of Arts and Culture to People and Societies an Evidence Review, Arts Council England publications. PDF available at: http://www.artscouncil.org.uk/what-we-do/research-and-data/value-artsand-culture-people-and-society-evidence-review/[Accessed March 2016] Odell-Miller H, Hughes P, Westacott M. (2006), 'An investigation into the effectiveness of the arts therapies for adults with continuing mental health problems.' Psychotherapy Research, 16 (1) : 122-139. 
Parr, H. (2012), 'The Arts and Mental Health: Creativity and Inclusion', Qualitative Research in Arts and Mental Health, T. Stickley (ed.) 2012, Ross-on-Wye: PCCS Books

Reason, P. \& Rowan, J. (Eds.) 1981), Human Inquiry; A sourcebook of new paradigm research, Chichester, UK: Wiley.

Ricoeur, P. (1986), 'Life: A story in search of a narrator,' in M. Doeser and J. Kray, (eds.), Facts and Values, Dordrecht: Martinus Nijhoff

Ricoeur, P. (1991), Life in quest of narrative, in D. Wood (ed) On Paul Ricoeur: Narrative and Interpretation. London: Routledge.

Sagan, O. (2015), "Hope crept in": a phenomenological study of mentally ill artists' biographic narrative". Journal of Mental Health, 24 (2) 73-77.

Sagan, O. (2014), Narratives of Arts Practice and Mental Wellbeing: Connection and Reparation: London: Routledge.

Sagan, O. (2011),' Thou Art: The multiple gaze of audio-visual, community-based participatory research' Journal of Applied Arts \& Health, 2 (2).

Sagan, O. (2010). Along the Continua: Mentally III Artists Uninterrupted, Chapter 1 in: Creativity: Fostering, Measuring and Contexts, Corrigan, A. M. (Ed.). Nuova: New York.

Scheff, T.J. (1999), Being Mentally III, (3 ${ }^{\text {rd }}$ edition), New York, NY: Aldline de Gruyter. Schiff, A. C. (2004), Recovery and Mental Illness: Analysis and Personal reflections Psychiatric Rehabilitation Journal 27 (3) 212 - 218.

Smith J.A., Harre, R., \& Van Langenhove, L. (1995), 'Rethinking Psychology'. London: Sage.

Spandler H, Secker J, Kent L, Hacking S, Shenton J. (2007), 'Catching life: the contribution of arts initiatives to recovery approaches in mental health.' Journal of Psychiatric Mental Health Nursing, 14 (8): 791-799.

Staricoff R. (2004), Arts in health: A review of the medical literature. London: Arts Council England.

Van Lith, T., Schofield, M.J., \& Fenner, P. (2013), 'Identifying the evidence-base for art-based practices and their potential benefit for mental health recovery: A critical review', Disability and Rehabilitation, 35, (16) : 1309-1323

Walsh, M. (2013), 'Art and Psychoanalysis', London: I.B. Tauris

White, M. (2009), 'Arts development in community health: A social tonic.'

London: Radcliffe. 
Wright, K. (2009), 'Mirroring and Attunement: Self-Realization in Psychoanalysis and Art.' Hove: Routledge. 